\title{
The Effects of Secondary Cancers on Survival in Patients with Breast, Lung and Prostate Cancer
}

\author{
(D) Alparslan MERDiN, ${ }^{1}$ (D) Hülya KARAKILINÇ, ${ }^{2}$ (D) Hakan Şat BOZCUK ${ }^{3}$ \\ 'Department of Internal Medicine, Akdeniz University Hospital, Antalya-Turkey \\ ${ }^{2}$ Department of Cancer Registry Unit, Health Directorate of Antalya Province, Antalya-Turkey \\ ${ }^{3}$ Department of Internal Medicine, Akdeniz University Hospital, Division of Oncology, Antalya-Turkey
}

\begin{abstract}
OBJECTIVE
The effects of subsequent primary cancers on survival analyses have been an area of clinical interest. This study aimed to evaluate the effects of subsequent primaries developed after the first primary tumor on the overall survival.

\section{METHODS}

We analyzed data on 6179 patients who had lung, breast or prostate cancer as their first primary cancer. All patients were recorded in the Cancer Registry Unit of the Health Directorate of Antalya Province of Turkey. We analyzed the data concerning each of the three first primaries. We utilised Kaplan-Meier survival analyses and log-rank test to compare the overall survival rates of patients with single primary tumors and patients with multiple primary tumors. In addition, we stratified data according to age, gender, number of primary tumors (patients with single primary, patients with multiple primaries), or disease stage of the first primary (metastatic, non-metastatic). Lastly, potential prognostic factors were separately evaluated in Cox-regression models.
\end{abstract}

\section{RESULTS}

We found that the overall survival of lung cancer patients with a single primary was shorter than that of patients with multiple primaries $(\mathrm{p}<0.001)$. It was vice versa for breast and prostate cancer patients. Multivariate analysis performed for lung cancer patients showed that male patients had a higher risk of exitus than female patients. Lung cancer patients who had metastatic disease at the time of diagnosis had a higher risk of exitus than patients who had a non-metastatic disease at the time of diagnosis $(\mathrm{p}<0.001)$.

\section{CONCLUSION}

We found that the inclusion of subsequent primary cancers in the overall survival analysis resulted in higher survival for the patients with lung cancer as their first primary tumor. On the other hand, it was associated with lower survival for patients with breast or prostate cancer as their first primary tumor.

Keywords: Breast cancer; lung cancer; multiple primary malignancies; prostate cancer; survival analysis. Copyright $\odot$ 2020, Turkish Society for Radiation Oncology

\section{Introduction}

Multiple cancers are defined as two or more cancers in the same or other organs of an individual patient, ei- ther synchronously or metachronously.[1] Each tumor must have a definite histologic picture of malignancy, be distinctly separated by an intact portion of the organ in case of multiple cancers in the same organ, and
Dr. Alparslan MERDiN

Akdeniz Üniversitesi Hastanesi,

İç Hastalıkları Anabilim Dalı,

Antalya-Turkey

E-mail: alparslanmerdin@gmail.com 
clearly have no metastatic origin from another tumor. [1] Subsequent primary tumors are divided into two categories as follows: synchronous and metachronous. Synchronous implies that the tumors detected within six months after the first malignancy. Metachronous tumors are defined as tumors detected after six months from the first malignancy.

Due to the improvement in diagnostic tools, treatment modalities and supportive care, survival time for cancer patients has been prolonged and the number of multiple primary cancers has increased continuously. Crocetti et al. reported that $1.08 \%$ of the cancer survivors were diagnosed with subsequent primary cancers.[2] However, clinicians treat all independent primaries, respectively, provided that the prior primary cancer has been successfully treated. Therefore, it is important to detect the subsequent primary cancers to treat earlier enough.

Rosso et al. reported that the general effects of the inclusion of multiple primary tumours in survival analyses is to reduce survival estimates.[3] Effects of inclusion of subsequent primary cancers in survival analyses are an area of clinical interest and further studies are needed. In this study, we planned to evaluate the effects of subsequent multiple primaries (MP) on the overall survival, following the diagnosis of breast, prostate and lung cancer.

\section{Materials and Methods}

In this study, we analyzed data on 6179 patients who had the diagnosis of breast, lung or prostate cancer as their first primary cancer. All patients included in this study had been diagnosed with malignancy between the years of 2005-2010 (the years 2005 and 2010 included). The last follow-up date was January 01,2012 . It was also the end of the study period. Diagnostic information on these patients' demographic and follow-up data were provided by Cancer Registry Unit of the Health Directorate of Antalya Province of Turkey ((Antalya İl Sağlık Müdürlüğü Kanser Kayıt Merkezi)(AİSMKKM)). AİSMKKM followed SEER (The Surveillance, Epidemiology, and End Results) rules for the definition of multiple cancer sites. The Surveillance, Epidemiology, and End Results (SEER) Program is part of the National Cancer Institute, USA.[4] We utilised Kaplan-Meier survival analyses to compare overall survival figures of patients with single primary tumors and patients with multiple primary tumors. Observed overall survival was calculated from the date of diagnosis of the first malig- nancy to last outpatient visit, loss of follow up, date of death or the end of the study period.

We also analyzed data concerning each three cancer primaries according to gender, number of independent primaries or disease extent of the first primary (metastatic, non-metastatic). Kaplan-Meier method was used for survival curves. Kaplan-Meier statistical method is a non-parametric estimator of the survival function.[5] A log-rank test was performed for comparison of overall survival between groups.[6] Besides, multivariate analyses were performed by cox-regression models.[7] SPSS18.0 (Statistical Package for Social Sciences, release 18.0) was used for the statistical analyses. Chi-square test was also used for statistical analyses. $\mathrm{P}<0.05$ was considered to be statistically significant. This study was approved by the local ethics committee.

\section{Results}

The findings showed that 1928 of all patients had breast cancer as the first primary and $1.50 \%$ (29) had multiple primaries. Among the 29 patients with multiple primaries, $69 \%$ (20) of them had metachronous and 31\% (9) of them had synchronous secondary malignancies. 2513 of all patients had lung cancer as the first primary and $1.15 \%$ (29) of them had multiple primaries. In addition, 1738 of the cases had prostate cancer as the first primary. Of patients with subsequent multiple primaries following lung cancer, 59\% (17) of them had metachronous, whereas $41 \%$ (12) of them had synchronous secondary tumors.

Estimated overall survival of lung cancer patients without secondary (subsequent was meant by using secondary) primaries was shorter than that of patients with multiple primaries $(\mathrm{p}<0.001)$ (Fig. 1). When multivariate analysis was carried out for lung cancer, male gender, having only one primary and having metastatic disease at the time of diagnosis were independently prognostic. Multivariate analysis showed that male patients had statistically higher risk of exitus than female patients. Patients who had metastatic disease at the time of diagnosis had a higher risk of exitus than patients who had a non-metastatic disease at the time of diagnosis $(\mathrm{p}<0.001)$. Patients who had only one primary cancers had also a higher risk of exitus than patients who had multiple primaries $(\mathrm{p}<0.001)$.

Survival analyses of prostate cancer patients whose primary malignancies were diagnosed between the years of 2005-2010 showed that estimated survivals of prostate cancer patients without secondary (sub- 


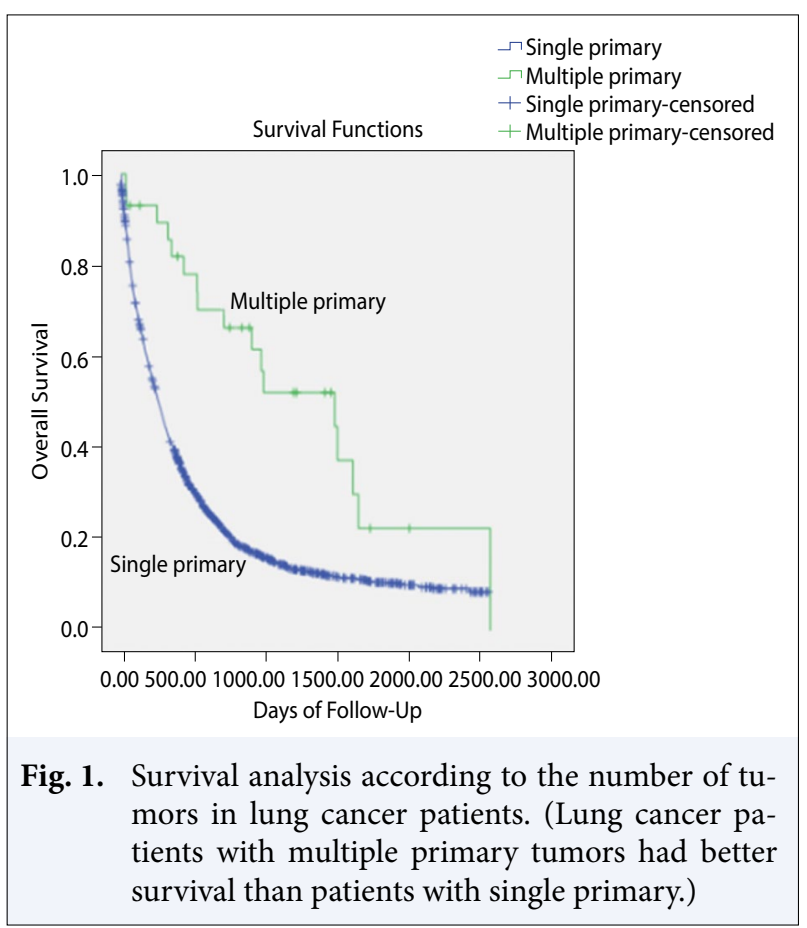

sequent was meant by using secondary) tumors were higher than that of patients with multiple primary tumors $(\mathrm{p}<0.05)$. Multivariate analysis done for these prostate cancer patients showed that patients who had metastatic disease at the time of diagnosis had a higher risk of exitus than patients who had the non-metastatic disease at the time of diagnosis $(\mathrm{p}<0.001)$. In addition to this, patients who had only one primary cancer also had higher risk of exitus than patients who had multiple primaries $(\mathrm{p}<0.001)$. Lastly, survival analyses of breast cancer patients whose primary malignancies were diagnosed between the years of 2005-2010 showed that estimated survivals of breast cancer patients without secondary (subsequent was meant by using secondary) tumors were higher than that of patients with multiple primary tumors $(\mathrm{p}<0.003)$. Multivariate analysis performed for these breast cancer patients showed that patients who had metastatic disease at the time of diagnosis had a higher risk of exitus than patients who had the non-metastatic disease at the time of diagnosis $(\mathrm{p}<0.001)$.

\section{Discussion}

Cancer multiplicity may be related to shared common etiologic factors, such as tobacco smoking, obesity, alcohol consumption, or genetically alterations, which increase the risk of second cancer developing in a patient already at high risk. For example, hereditary non-polyposis colorectal cancer individuals are at an increased risk of developing other tumor types, such as cancers of the endometrium, urothelium and small intestine. Survivors of all cancers now live for longer periods, partly because of the more frequent use of radiation and chemotherapy. Australian Institute of Health and Welfare also reported that five-year survival from all cancers increased from $47 \%$ in the period 1982-1987 to 66\% in 2006-2010.[8]

Rosso et al. reported cancer multiplicity frequency among cancer patients in Europe with an overall proportion of $6.3 \%$.[3] Ueno et al. reported that $1281(5.3 \%)$ of the 24498 cancer patients treated at the Cancer Institute Hospital developed a second cancer. [1] Bhaskarla et al. reported that $1.5 \%$ of the patients with lung cancer developed a second primary.[9] Artac et al. reported that metachronous secondary cancers were more frequent than synchronous secondary cancers.[10] From this perspective, our results comply with the aforementioned literature. $[9,10]$

In the literature, Ellison analyzed Canadian data and reported a lower survival in multiple primary cancers.[11] Brenner and Hakulinen [12] used data from the Finnish Cancer Registry and reported similar results with Ellison.[11] Rosso et al. found that agestandardized 5-year survival estimates for 1995-1999 were systematically lowered by the inclusion of second and subsequent primary cancers.[3] Aguilo et al. reported that lung cancer survival varied according to lung cancer stage and that no higher risk of death was related to cancer multiplicity.[13] Besides, we showed that including subsequent multiple primary tumors to survival analyses of lung cancer patients indicated a better prognosis. In a study involving women patients diagnosed with breast cancer, Raymond et al. reported that overall survival was poorer for women with multiple primary tumors compared with women with single primary tumor.[14] We also showed that cancer multiplicity is associated with worse prognosis in patients who had breast or prostate cancer as the first primary. From this perspective, our results also fit in with the study of Raymond et al.[14] In accordance with these findings, it seems that lung cancer patients who had subsequent tumors might have a tendency to live longer compared with lung cancer patients who had no second tumors.

Our study also had several limitations because this study was conducted by the retrospective analysis of the patients. Reachable data provided by the registry unit were only used in the study. However, data collec- 
tion to the registry of AİSMKKM was still ongoing at the time of data gathering. Inclusion of new patients and new data to the registry of AİSMKKM was going on during the time the data included in this study was given by the registry unit, which was one of the reasons we chose the year 2005, not before. At the time data was given by the registry unit, it was informed that records of years before 2005 were incomplete. Furthermore, overall survival was evaluated in our study. Cancer-specific survival was not analyzed. Overall survival could be affected by the presence of comorbidities, particularly cardiovascular diseases, diabetes mellitus and/or smoking.[15] In any case, subsequent tumors are not just numerical changes of tumor numbers. They could also be determinants of prognosis. Besides, further studies are needed to assess the effects of subsequent tumors on survival.

\section{Conclusion}

In conclusion, careful attention should always be given to the development of subsequent primary cancers during the treatment and follow-up of cancer patients. Patients with cancer should be informed by physicians about the risk of the development of secondary neoplasms. Appropriate screening tests for the early diagnosis of secondary malignancies should not be neglected and clinicians should not hesitate to obtain biopsies from suspected lesions. With careful monitoring, secondary tumors can be detected earlier, and with appropriate intervention, may be better managed.

Acknowledgements: We would like to express our gratitude towards to Cancer Registry Unit of the Health Directorate of Antalya Province of Turkey (Antalya İl Sağllk Müdürlügü Kanser Kayit Merkezi) for providing us with their data. As the corresponding author of this study, I also want to thank my wife Fatma Avcı Merdin, for sharing her love and time during this period. Some of the related data of this study were presented as an abstract at the European Cancer Congress (ECCO 17, ESMO 38) September 27-October 1, 2013, Amsterdam, Holland. Related published Congress abstract no. Po1430 in Eur J Cancer 2013:49(Suppl 2). In addition, the corresponding author also wants to thank his father Hayri Merdin, his mother Zeynep Merdin and his brother Mustafa Kürşat Merdin for sharing their time. Lastly, the authors thank Health Directorate of Antalya Province of Turkey (Antalya İl Sağlık Müdürlügü) for their permission to use the data of the Health Directorate of Antalya Province of Turkey.

Peer-review: Externally peer-reviewed.
Conflict of Interest: There are no conflicts of interest in this study.

Ethics Committee Approval: This study was approved by the local ethics committee.

Financial Support: We do not have any financial support for this study.

Authorship contributions: Concept - A.M., H.Ş.B.; Design - A.M., H.Ş.B.; Supervision - A.M., H.K., H.Ş.B.; Funding - A.M.; Materials - A.M., H.Ş.B., H.K.; Data processing - A.M., H.K., H.Ş.B.; Data gathering/collection from the Cancer Registry Unit of the Health Directorate of Antalya Province of Turkey - H.K.; Data analysis and/or interpretation - H.Ş.B.; Literature search - A.M., H.Ş.B.; Writing A.M., H.K., H.Ş.B.; Critical review - A.M., H.K., H.Ş.B.

\section{References}

1. Ueno M, Muto T, Oya M, Ota H, Azekura K, Yamaguchi T. Multiple primary cancer: an experience at the Cancer Institute Hospital with special referance to colorectal cancer. Int J Clin Oncol 2003;8(3):162-7.

2. Crocetti E, Buiatti E, Falini P; Italian Multiple Primary Cancer Working Group. Multiple Primary Cancer Incidence in Italy. Eur J Cancer 2001;37(18):2449-56.

3. Rosso S, De Angelis R, Ciccolallo L, Carrani E, Soerjomataram I, Grande E, Zigon G, Brenner H; EUROCARE Working Group. Multiple tumours in survival estimates. Eur J Cancer 2009;45(6):1080-94.

4. https://seer.cancer.gov

5. Kaplan E, Meier P. Non parametric estimation from incomplete observations. J Am Stat Assoc 1958;53:457-81.

6. Mantel N. Evaluation of survival data and two new rank order statistics arising in its consideration. Cancer Chemother Rep 1966; 50: 163-70.

7. Cox, D. R. "Regression Models and Life-Tables." Journal of the Royal Statistical Society. Series B (Methodological), vol. 34, no. 2, 1972, pp. 187-220.

8. Australian Institute of Health and Welfare. Cancer survival and prevalence in Australia: Period estimates from 1982 to 2010. Asia Pac J Clin Oncol 2013;9(1):29-39.

9. Bhaskarla A, Tang PC, Mashtare T, Nwogu CE, Demmy TL, Adjei AA, et al. Analysis of second primary lung cancers in the SEER database. J Surg Res 2010;162(1):1-6.

10. Artac M, Bozcuk H, Ozdogan M, Demiral AN, Sarper A, Samur M, et al. Different clinical features of primary and secondary tumors in patients with multiple malignancies. Tumori 2005;91(4):317-20.

11. Ellison LF. Measuring the effect of including multiple cancers in survival anlayses using data from 
the Canadian Cancer Registry. Cancer Epidemiol 2010;34(5):550-5.

12. Brenner $\mathrm{H}$, Hakulinen T. Patients with previous cancer should not be excluded in international comparative cancer survival studies. Int J Cancer 2007;121(10):2274-8.

13. Aguiló R, Macià F, Porta $M$, Casamitjana $M$, Minguella J, Novoa AM. Multiple independent primary cancers do not adversely affect survival of the lung cancer patient. Eur J Cardiothorac Surg 2008;34(5):1075-80.

14. Raymond JS, Hogue CJR. Multiple primary tumours in women following breast cancer, 1973-2000. Br J Cancer 2006;94(11):1745-50.
15. Ryu JS, Choi CM, Yang SC, Song SY, Jeon YJ, Jang TW, et al. Prognostic effect of age on survival of patients with stage 1 adenocarcinoma of the lung. Tumori 2012;98(1):99-104.

Footnotes: The corresponding author's working address during the submission of the article was Hematology Clinic and Bone Marrow Transplantation Unit, University of Health Sciences Ankara Dr. Abdurrahman Yurtaslan Oncology Education and Research Hospital. In addition, this study was derived from and based on the thesis work (Medical Specialty Thesis, University of Akdeniz, Antalya, Turkey) of the author Alparslan Merdin. 